\title{
Sobre os capillares de secreção ou cytosolenulos das glandulas gastricas proprias dos Dasypodidae (Tatús)
}

(Communicacão com apresentaç̃o de preparados, feita á Sociedade de Medicina e Cirurgia de S. Pauło, na sessão de 15-6-1921)

POR

MARCOS LINDENBERG E MOACYR DE F. AMORIM

4.0 ANNISTAS

Não temos a menor pretenção de levar ao conhecimento desta sociedade alguma novidade absoluta; desejamos simplesmente apresentar alguns preparados aprestados a conselho do Dr. Bovero yara o fim de demonstraç̧ões didacticas. Talvez sómente a especie animal na qual tentámos as nossas pesquizas, especie essa tão caracteristica da fáuna sul-americana, ou mesmo a ordem dos Desdentados não foram ainda explorados nesse sentido.

Trata-se dos apparelhos endo e intercellulares de secreção que teem o nome de E. Müller-Golgi, nas cellulas parietaes ou delomorphas ou oxynticas das glandulas gastricas proprias dos Tatús; esse apparelho em geral bem conhecido dos histologos é na maioria dos iratados ou em monographias especiaes bem descripto, com figuracões minuciosas das suas particularidades.

Canaes de excreção ou de secreção endo e intercellulares não são além disto exclusivos das glandulas gastricas proprias; nestas certamente adquirem, particularmente os canaliculos endocellu. lares a sua maxima complexidade; mas encontram-se tambem nas cellulas das glandulas serosas da lingua (Fusari e Panasci), nas cellulas serosas das glandulas salivares mixtas (Cajal e Van Gehuchten), nas cellulas exocriras dos tubos pancreaticos (Cl. Sela), nos cellulas hepaticas (Oppel e outros).

O apparelho que nos occupa foi descripto primeiramente para az glandulas gastricas pepticas por Erik Müller (1892), o qual conse- 
guiu demonstral-o usando do methodo de impregnação de Golgi; logo depois e independentemente de Müller, Golgi (1893), com o mesmo seu methodo, não sómente confirmou os resultados de E. Müller mas conseguiu demonstrar outras particularidades correspondentes a differentes condições physiologicas cellulares de digestão e de jejum; Golgi admittia que o apparelho apparecesse principalmente sob a forma de cestas pericellulares; Müller porém (1894 e 1898), voltando ao assumpto, demonstrou que os canaliculos são em verdade endocellulares. Aos mesmos resultados chegaram tambem Zimmermann e R. Monti (1898), esta ultima nos peixes, reptis e amphibios.

Estudos mais minuciosos e mais completos sobre este assumpto pertencem sem duvida aos dois irmãos Rina e A. Monti, os quaes cscolheram como material de estudo dos cytosolenulos - assim elles chamam os canaliculos de secreção - um Myomrpho, o Arctomys Marmota, no intuito de verificar as modificações do apparelho em questão nas differentes phases funccionaes: na actividade digestiva e no jejum completo, qual se verifica no lethargo hibernal.

Rina e A. Monti demonstraram que ao passo que nas cellulas delomorphas da Marmota em actividade os cytosolenulos constituem elegantissimas cestas canaliculares ligadas á luz glandular por um pedunculo, durante o lethargo os mesmos não desapparecem, mas reduzem-se apenas constituindo então clavas ou anneis simples, raramente multiplos em relação a cada cellula delomorpha: estes estudos assentaram definitivamente que os cytosolenulos devem ser considerados como formações estaveis da cellula delomorpha, e isso em desaccordo com os AA. que, como Von Brunn (1894), admittiam que as finas vias de secrecção não fossem canaes preformados, e sim a expressão de accidentae $_{S}$ correntes de secrecção surprehendides pela fixação.

Ainda dos estudos de Rina e A. Monti resulta que os cytosolenulos, seja na acividade, seja no repouso são sempre totalmente endocellulares; elles não apresentam membrana propria; são pelo contrario verdadeiras vias excavadas no seio do protoplasma.

A's mesmas formações canaliculares endocellulares ou capillares intracellulares demonstraveis pelos processos de impregnacão faz iambem ligeira referencia C. Pinheiro Chagas, o qual (1920) affirma que na cobaya esses canaliculos se mostram nitidos nas preparações que obteve por injecções vitaes d? vermelho neutro.

Deixando de lado os estudos de Rina e A. Monti nos vertebrados inferiores e considerando somente os Mamiferos alem da Marmota (R. e A. Monti), e da cobaya (Chagas), os cytosolenulos foram encontrados, com ligeiras differenças em cada especie, por E. Mül- 
ler no cachorro, gato e porco, por Golgi no coelho, por Zimmermann no cachorro, gato, cavallo, e homem.

Ao nosso conhecimento nada existe na literatura sobre este assumpto que possa referir-se aos Mamiferos exquisitamente néoarcticos como a maioria dos grupos dos Desdentados e alguns Marsupiaes; com esta constatação se pode, ainda uma vez indicar larguissimos campos de estudo.

No intuito de obter os preparados que apresentamos utilisamonos da mucosa gastrica do commum Tatú dos nossos campos (Tatusia Novemcyncta ou Dasypus Novemcynctus), com o conhecido nethodo rapido de impregnação osmio-chromo-argentica de Golgi, cuja notoriedade e simplicidade dispensam-nos, naturalmente, de referencias mais amplas.

Aos preparados obtidos com esse methodo, juntamos sobre os cortes colorações nucleares communs com o fim de evidenciar as relações entre os cytosolenulos e os outros constituintes cellulares.

Com o methodo de Golgi, como é sabido, a impregnação dos cytocolenulos, como tambem das outras particularidade morphologicas ou cytologicas cuja demonstração depende precisamente das precipitações metallicas, nem sempre se dá em todas as glandulas, nem e'm cada glandula em todas as cellulas delomorphas.

Quando a impregnação é completa e o corte parallelo ao eixo de slandula, analogamente a quanto acontece nos outros Mamiferos, tambem nos Tatús a luz das glandulas gastricas proprias apparece em forma de um esteio, de cor preta ou parda mais ou menos intensa, segundo a expessura do corte e a maturidade da reacção. Seu percurso é ora sinuoso, ora em zig-zags, com nodosidades mais ou menos accentuadas. Geralmente não existem ramificações, particularmente ma parte correspondente ao corpo ou fundo glandular; só em algumas vezes nos foi possivel verificar uma bifurcação na região do collo, logo abaixo do ephitelio de revestimento e, porisso, perto das ?ryptas gastricas, como si duas glandulas se reunissem num pequeno tractus commum; entretanto pelo menos até agora, as ramificações secundarias e tambem terciarias tão frequentes, descriptas por Rina. e A. Monti na Marmota, não occorrerari á nossa obesrvacão nos Tatús. Deste modo, rrecisamente como Rina e A. Monti affirmam, a glandula em conjuncto "lembra uma espiga cujo esteio traz por meio de outros tantos pedunculos pequenos cestos" Os pequenos pedunculos decorrem nos intersticios das cellulas principaes ou pepsinogenicas; os cestos correspondem ás cellulas parietaes, ou delomorphas ou oxynticas.

Nos nossos melhores preparados de Tatús esses cestos com os respectivos pedunculos podem apparecer em numero de 25 a 30 para cada glandula; cada cesto com o seu peduncuio é, habitualm mais ou menos redondo ou conico; as alças canaliculares podem dar 
MUCOSA GASTRICA DE TATU'

(Methodo rapido de Golgi)

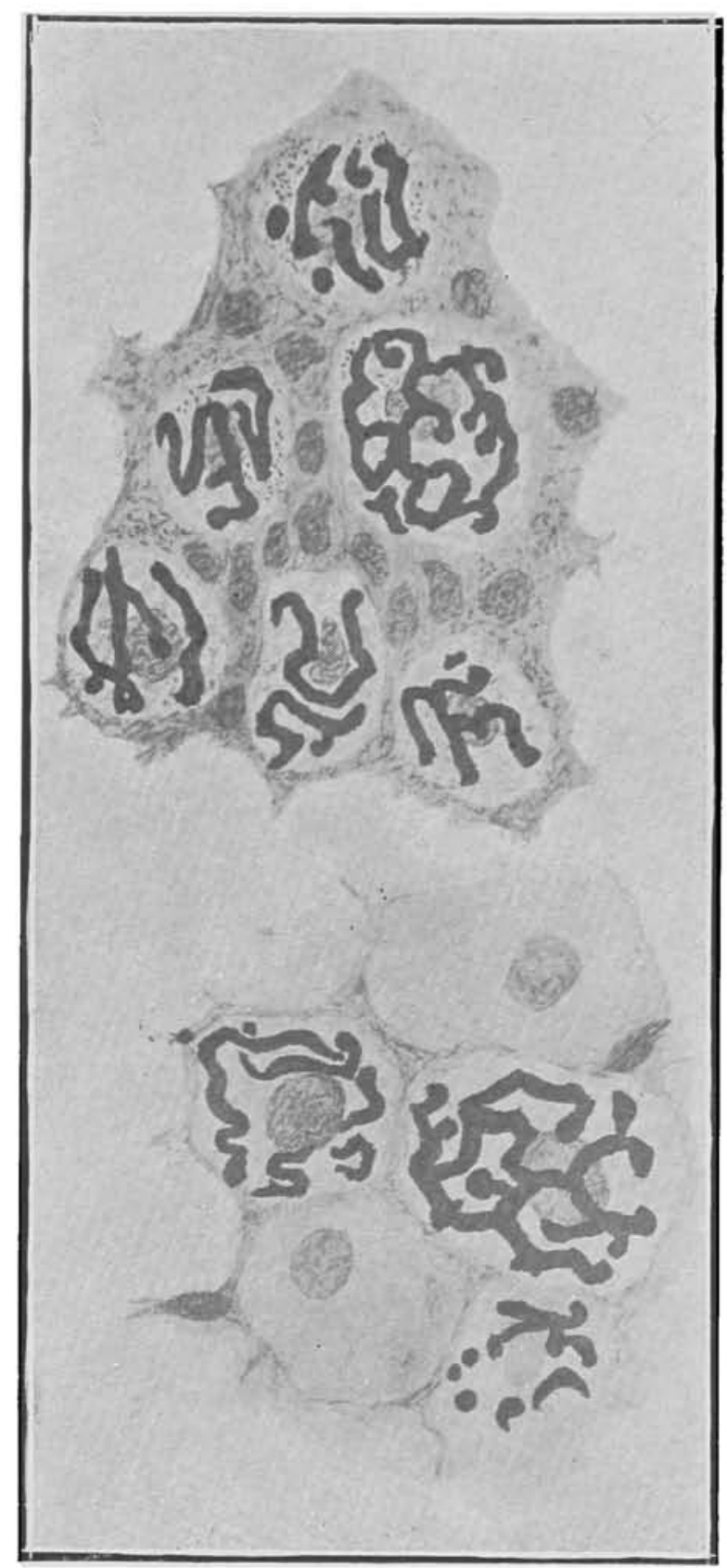

Rêdes enlio-cellulares ou cytosolenulos 

Mucosa gastrica de tatú.

Córte longitudinal de glandula gastrica propria.

(METHODO RAPIDO DE GOLGI)

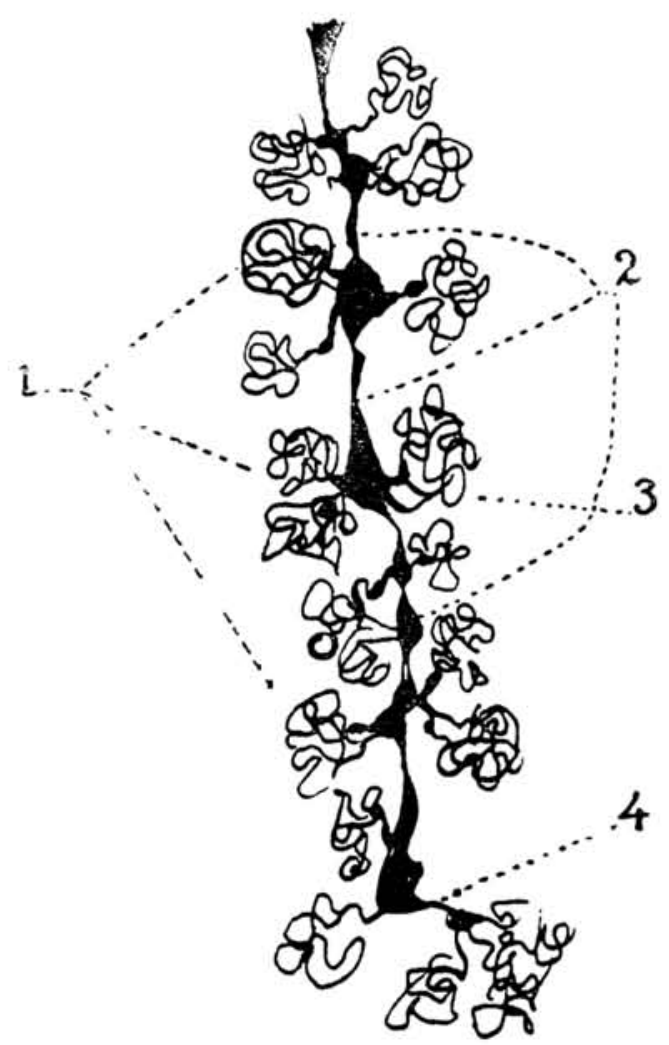

1 .. Rêdes rndo-cellula-

4.. Pedunculo que une res ou cytosolenulos. a rêde endo-celullar 2 .. Ducto glandular.

3 .. Peduncilo duplo. á luz glandular. O pedunculo $\dot{e}$ ramificado. 

o aspecto de uma poly-lobulação. Dá-nos a impressão que a rede dos canaliculos por nós obtidos nos Tatús, confrontados com as figuras dos AA. e particularmente com as de Rina e A. Monti, sejam de modo geral ligeiramente mais simples, isto é, que as malhas sejam menos apertadas e numerosas; note-se entretanto que o nosso material provem de animaes engaiolados algum tempo, e, todos aqui sabem como é difficil alimentar os Tatús quando captivos. Certo porem os mesmos canaliculos estão bem longe da extrema simplicidade occurrente nas Marmotas em lethargo.

o pedunculo que une a cesta á luz glandular é geralmente unico, kilgumas vezes porem duplice; neste caso cada um por sua vez chega á luz glandular; ou emfim úm pedunculo em uma parte de seu percurso, entre duas cellulas adelomorphas, se divide em dois, tres ramos que se continuam na rede canalicular endocellular.

Os cytosolenulos, como já foi repetidas vezes descripto, rodeiam o nucleo mais ou menos completamente, deixando livre uma certa porção de cytoplasma perinuclear; as alças capillares correspondem principalmente á parte peripherica do cytoplasma.

As relações da cesta dos cytosolenulos com o nucleo são bem visiveis nos preparados corados após a impregnação, como aquelles que apresentamos. Não raramente das malhas da cesta, se originam raanos que dirigindo-se para o centro se treminam em fundo cego, geralmente um pouco dilatedos em clava ou bóla.

$\mathrm{O}_{\mathbf{s}}$ canaliculos endocellulares apparecem ainda nas cellulas oxynticas tambem sem impregnação, por exemplo com a coloração principe da hematoxylina ferrica segundo Heidenhein: emquanto com ksta coloração sejam necessarios cortes muito finos, é, possivel em casos opportunos, demonstrar a topographia das alças canaliculares sm relação ao nucleo e á peripheria da cellula, como foi dito resultar do exame dos preparados impregnados e secundariamente corados.

0 pedunculo tem talvez diametro oscillante entre 1 e 2 micra; é maior quando unico, sem duvida menor quando duplice. Tambem os pedunculos intercellulares apresentam aqui e alli pequenas dilatações e nem sempre têm decurso perfeitamente rectilineo, mas sim jigeiramente sinuoso. O diametro dos cytosolenulos é em geral, ligeiramente menor; mede de 1 a 1,5 micra; algumas vezes porém não npparece nenhuma differença entre o calibre do pedunculo e o calibre de porções relativamente extensa: dos constituintes da rede *ndocellular; pelo contrario, em falta de mensurações minuciosas, podemos affirmar que se tem a impressão algumas vezes de que, pelo menos por uma certa extensão, os cytosolenulos, considerados separadamente sejam ainda mais grossos que o pedunculo resultante dos ramos da rede endoceilular

Parece-nos que as particularidades por nós observadas, por quanto 
representem essencialmente a confirmação dos achados dos outros AA. em outros Mamiferos, muito differentes pela assim chamada bierarchia zoologica, certo muito diversos tambem pelos habitos e constituição morphologica, podem ter um certo valor, não sómente qor augmentarem os nossos conhecimentos, como tambem por demonstrarem particularidades mais conhecidas pela leitura de quanto está consignado nos tratarlos, que pela observação directa.

Obtivemos muito facilmente os nossos preparados, e porisso reservamo-nos de extender as nossas pesquizas aos outros Desdentados e aos Marsupiaes, tendo tambem como argumento collateral, por emquanto ainda quasi virgem, a distribuição no estomago desses Mamiferos das varias categorias de glandulas gastricas.

Do Laboratorio de Histologia da Faculdade de Medicina e Cirurgia de S. Paulo. 